Presented at Fall Meeting of the Materials Reseach Society, Boston, MA, December 1-5, 1997; to be published in:

Microscopic Simulation of Interfacial Phenomena in Solids and Liquids, ed. by P. D. Bristowe, S. R. Phillpot, D. G. Stroud, and J. R. Smith Materials Research Society, Warrendale, Pennsylvania.

First-Principles Simulations and Z-Contrast Imaging of Impurities at $\langle 001\rangle$ Tilt Grain Boundaries in MgO

Y. Yan, ${ }^{1}$ M. F. Chisholm, ${ }^{1}$ G. Duscher, ${ }^{2}$ S. J. Pennycook, ${ }^{1}$ A. Maiti ${ }^{3}$ and S. T. Pantelides ${ }^{4}$

${ }^{1}$ Solid State Division, Oak Ridge National Laboratory

P.O. Box 2008, Oak Ridge, Tennessee 37831-6030

2Department of Physics, University of nlinois at Chicago

Chicago, Illinois 60607-7059

${ }^{3}$ Molecular Simulations Inc., 8 N.E. Executive Park Burlington, MA 01803-5297

${ }^{4}$ Department of Physics and Astronomy, Vanderbilt University

Nashville, TN 37235

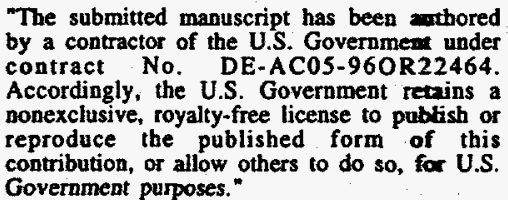

Government purposes."

prepared by

SOLID STATE DIVISION

OAK RIDGE NATIONAL LABORATORY

Managed by

LOCKHEED MARTIN ENERGY RESEARCH CORP.

under

Contract No. DE-AC05-96OR22464

with the

U.S. DEPARTMENT OF ENERGY

Oak Ridge, Tennessee

December 1997 


\section{DISCLAIMER}

This report was prepared as an account of work sponsored by an agency of the United States Government. Neither the United States Government nor any agency thereof, nor any of their employees, makes any warranty, express or implied, or assumes any legal liability or responsibility for the accuracy, completeness, or usefulness of any information, apparatus, product, or process disclosed, or represents that its use would not infringe privately owned rights. Reference herein to any specific commercial product, process, or service by trade name, trademark, manufacturer, or otherwise does not necessarily constitute or imply its endorsement, recommendation, or favoring by the United States Government or any agency thereof. The views and opinions of authors expressed herein do not necessarily state or reflect those of the United States Government or any agency thereof. 


\section{DISCLAIMER}

Portions of this document may be illegible electronic image products. Images are produced from the best available original document. 


\title{
FIRST-PRINCIPLES SIMULATIONS AND Z-CONTRAST IMAGING OF IMPURITIES AT <001> TILT GRAIN BOUNDARIES IN MGO
}

\author{
Y. YAN ${ }^{1}$, M.F. CHISHOLM' ${ }^{1}$, G. DUSCHER ${ }^{1,2}$, S.J. PENNYCOOK', A. MAITI ${ }^{3}$ AND \\ S.T. PANTELIDES 1.4 \\ I Solid State Division, Oak Ridge National Laboratory, Oak Ridge, TN 37831 \\ ${ }^{2}$ Department of Physics (M/C 273), University of Illinois at Chicago, Chicago, II 60607 \\ ${ }^{3}$ Molecular Simulations Inc., 8 N. E. Executive Park, Burlington, MA 01803-5297 \\ 4 Department of Physics and Astronomy, Vanderbilt University, Nashville, TN 37235
}

\section{ABSTRACT}

First-principles density-functional calculations were used to study the effects of $\mathrm{Ca}$ impurities on the $\Sigma=5(310)<001>$ tilt grain boundaries in $\mathrm{MgO}$. An equilibrium structure and two metastable structures of the grain boundaries in pure $\mathrm{MgO}$ have been established. The calculations further demonstrated that $\mathrm{Ca}$ impurities segregate at particular sites in the metastable grain boundary and induce a structural transformation. This result is consistent with atomic resolution Z-contrast imaging. The calculations also found that the impurities at the grain boundaries do not induce states in the band gap. The mechanism of the transformation is also discussed.

\section{INTRODUCTION}

Impurity segregation in grain boundaries not only changes the chemistry of the grain boundaries, but may change the structure also. Thus, the mechanical, electrical and optical properties of polycrystalline materials can be altered in a dramatic way [1-5]. Theoretical simulations have been used extensively to model grain boundaries and understand effects of impurities on grain boundaries. Recently, we have directly observed the structure of an impurity segregated $<001>$ tilt grain boundary in $\mathrm{MgO}$ by the use of Z-contrast imaging. High spatialresolution electron energy loss spectroscopy demonstrated that the impurity is Ca. The structure we observed disagrees with the model proposed by empirical potential calculations for a grain boundary in pure $\mathrm{MgO}$. In the present paper, we report first-principles density-functional calculations of the effects of $\mathrm{Ca}$ impurities on the $\Sigma=5(310)<001>$ tilt grain boundaries in $\mathrm{MgO}$ and demonstrate that $\mathrm{Ca}$ segregation induces a structural transformation of the grain boundary.

\section{METHOD}

The calculations were based on density functional theory with the exchange-correlation energy treated in the local density approximation [6,7]. Norm-conserving Pseudopotentials were defined on a real-space grid. The calculations were performed using the code CASTEP. An energy cutoff of $600 \mathrm{eV}$ was used, and the integration over the Brillouin zone was performed using three special $k$ points chosen according to the Monkhorst-Pack scheme. For each geometry the electronic wave functions were first relaxed by the conjugate gradient scheme of Payne et al. [8]. Atoms were then fully relaxed according to the Hellman-Feynman forces until the largest force on any ion in any direction was less than $0.1 \mathrm{eV} / \AA$. The cell dimensions were optimized until the largest displacement was less than $0.01 \AA$. We used periodic supercells that contain two oppositely oriented $\Sigma=5(310)$ grain boundaries. The grain boundaries are parallel to the $\{310\}$ plane of the original crystalline lattice. They have a periodicity of one conventional lattice parameter $(a=4.211 \AA)$ in the $<001>$ direction and a periodicity of $6.64 \AA$ in the direction perpendicular to $<001>$ axis. The two grain boundaries are separated by $13.4 \AA$, twice the distance between neighboring dislocation cores, and each cell contains $40 \mathrm{Mg}$ and $40 \mathrm{O}$ atoms. 


\section{RESULTS AND DISCUSSION}

\section{Structures of Grain Boundaries in Pure MqO}

$\mathrm{MgO}$ has the $\mathrm{NaCl}$ structure (Fm $\overline{3} \mathrm{~m}$ ) with a lattice parameter of $0.4211 \mathrm{~nm}$. In $\mathrm{NaCl}$ type metal oxides such as $\mathrm{MgO}$ and $\mathrm{NiO}$, grain boundaries, especially the $<001>$ tilt symmetric ones have been studied by both theoretical simulations and high-resolution phase contrast transmission electron microscopy (HREM) [9-13]. Figure 1A shows the model first proposed by Kingery as a possible representation of the $36.87^{\circ}$ symmetric $<001>$ tilt boundary $\left(\sum=5(310)<001>\right.$ ) in $\mathrm{NaCl}-$ type metal oxides [9]. This boundary core is similar to that found in f.c.c. metals. However, static-lattice simulations using interatomic potentials that include the polarizability of oxygen ions in the shell model, showed that this structure is not energetically favorable in pure NiO and $\mathrm{MgO}$ $[10,11]$. These simulations showed that the series of (n10) $<001>$ symmetrical tilt grain boundaries in both $\mathrm{NiO}$ and $\mathrm{MgO}$ are qualitatively similar and can be considered as arrays of a single structural unit combined with perfect crystal spacer units. Figure 1B shows the atomic configuration for this structural unit proposed by the static-lattice simulations for a $\Sigma=5$ (310) $<001\rangle$ tilt grain boundary. It is seen that structural unit of this boundary is relatively open when compared with Kingery's model (we call these two structures open and dense, hereafter). Phase contrast HREM observations have revealed the structures similar to those proposed by the staticlattice simulations in the pure thin film $\mathrm{MgO}$ grain boundaries [12]. Our Z-contrast images on $\mathrm{MgO}$ bicrystals show the dense structure (Fig. 1D). In additional, the dense structure with a displacement (Fig. 1C) on the boundary plane $\{310\}$ was used to explain the HREM image of grain boundary obtained in $\mathrm{NiO}[13,14]$.

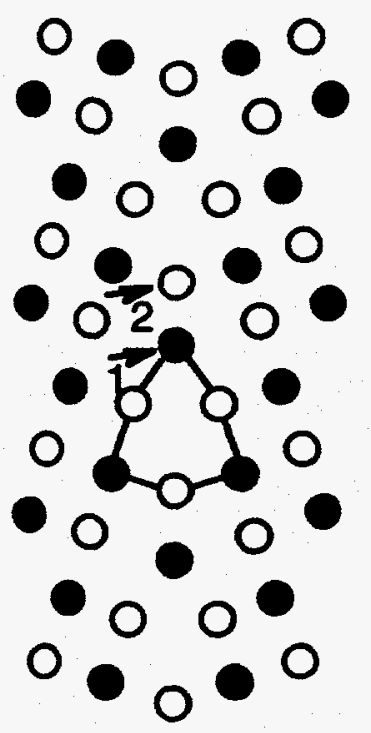

A

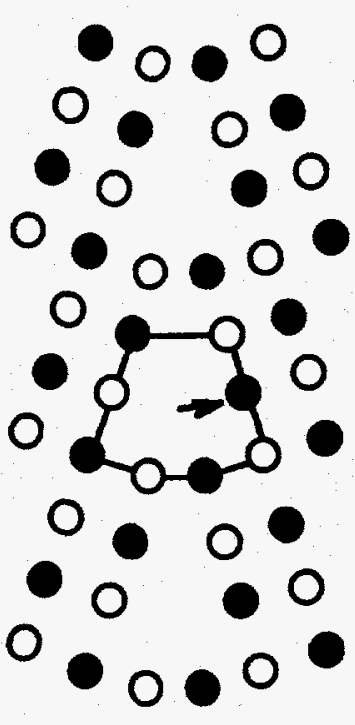

B

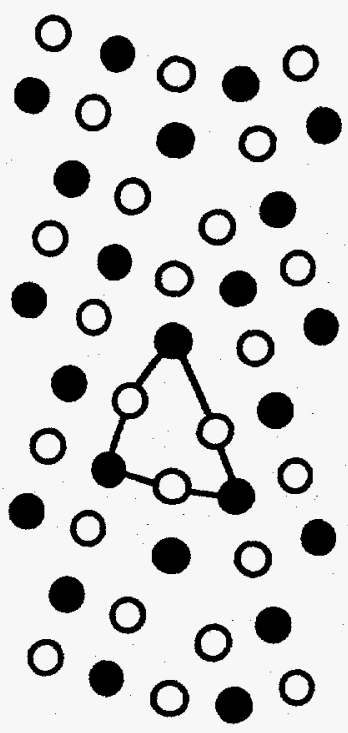

C

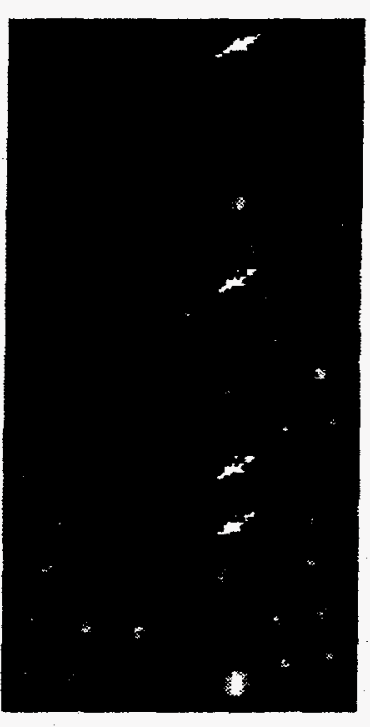

D

- Mg O O

Fig. 1: Models for the $\Sigma=5(310)<001>$ tilt grain boundary in $\mathrm{Mg} O$, the dense structure (A), the open structure (B) and the dense structure including a shift $\mathbf{R}$ in the boundary plane (C); D Experimental Z-contrast image showing the A structure. 
The calculations were performed on four structures for the pure grain boundaries in $\mathrm{MgO}$, the dense and open structures with and without displacement $\mathbf{R}$ in the $(310)$ plane. It was found that the open structure with displacement $\mathbf{R}$ is unstable, and spontaneously reverts to the open structure without any displacement. Of the other three structures, the open structure has the lowest total energy, in agreement with previous calculations [11]. However, we found that the dense structure with and without the displacement $\mathbf{R}$ are both metastable. The local minimum in energy was obtained at $\mathbf{R}=0.084<310>$ by the calculations. It should be noted that this dense structure with the displacement $\mathbf{R}$ explains the HREM image of the asymmetric grain boundary in NiO.

Fig. 2A, 2B, 2C and 2D shows the total density of states (TDOS) calculated for bulk MgO and the three grain boundaries shown in Fig. 1A, 1B and 1C. It is seen that the TDOS of the three grain boundaries are very similar to that of the bulk crystal, suggesting no major change in the electronic structure induced by these grain boundaries. The TDOS also shows that the grain boundaries do not change the width of the band gap and do not induce electronic states in the gap.
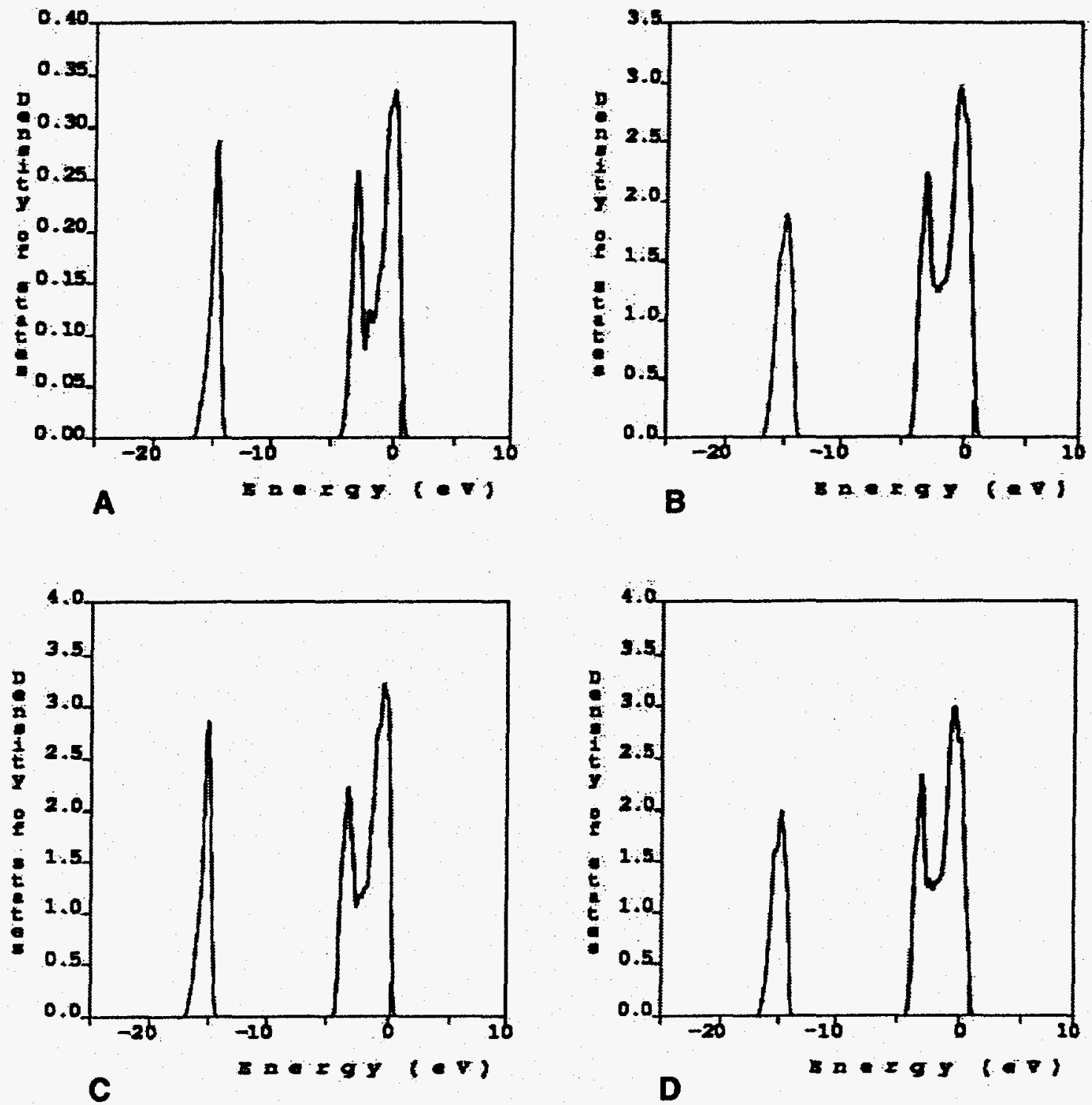

Fig. 2 Total density of states calculated for $\mathrm{MgO}$ Bulk (A), dense structure (B), open structure (C), and dense structure with displacement $R=0.0839<310>$ (D). No significant difference is observed. 


\section{Effects of Ca Impurity on the Grain Boundaries}

While both the ionic shell model simulations and some phase contrast HREM observations of $<001\rangle$ tilt grain boundaries in pure $\mathrm{NaCl}$-type oxides indicate that the open unit is the equilibrium configuration, our Z-contrast image provides a different result. Of the three proposed models, our experimental observations most closely match the model proposed by Kingery. It is also noted that in the Z-contrast image certain columns in the boundary are brighter than their neighbors. This implies that impurity elements with atomic numbers greater than that of $\mathbf{M g}$ $(\mathrm{Z}=12)$ are segregated to these sites. Using high spatial resolution electron energy loss spectroscopy we have determined that the impurities are $\mathrm{Ca}$ atoms. No other impurities were detected at the boundary. It is important to note that $\mathrm{Ca}$ segregates to particular columns in the boundary structural units. This suggested that the segregation of $\mathrm{Ca}$ induces a structural transformation of the $\mathrm{MgO}$ grain boundary core from the open structure to a more dense structure. First principles calculations were performed to understand this transformation.

Firstly, the calculations demonstrated that $\mathrm{Ca}$ impurities segregate at particular columns in the dense structure. It was found that the calculated total energy for Ca segregated at column 1 (see Fig. 1A) is $0.4 \mathrm{eV}$ lower than Ca segregated at column 2 in the dense structure. This result is in agreement with that obtained from the Z-contrast images. The preferred site for $\mathrm{Ca}$ segregation in the open structure was found by bond-valence sum calculation $[15,16]$ and is marked by an arrow in Fig. 1B. The presence of $\mathrm{Ca}$ at the boundary does not affect the character of the dislocation array of the boundary, nor does it affect the relative positions of the adjacent grains. In both structures, Ca prefers boundary sites with the largest nearest neighbor distances. Defining the $\mathrm{Ca}$ segregation energy as $E_{s e g r}=\frac{1}{2}\left(E_{i}-E_{i \text { pare }}-2 E_{C_{2 O} M_{g O}}+2 E_{M g O M g O}\right)$, where $E_{i}$ is the total energy of the $\mathrm{Ca}$ doped structure, $\mathrm{E}_{\mathrm{i} \text { pure }}$ is the total energy of the pure boundary structure, $\mathrm{E}_{\mathrm{CaO}_{2} \mathrm{MgO}_{8}}$ is the energy of $\mathrm{CaO}$ in bulk $\mathrm{MgO}$ and $\mathrm{E}_{\mathrm{MgOMgo}}$ is the energy of a $\mathrm{MgO}$ molecule in bulk $\mathrm{MgO}$, we find for the dense structure, $\mathrm{E}_{\text {segr }}=-1.2464 \mathrm{eV} / \mathrm{Ca}$ atom and for the open structure, $\mathrm{E}_{\text {segr }}=-0.9571$ $\mathrm{eV} / \mathrm{Ca}$ atom. This driving force for segregation is reflected in the excess energy associated with the grain boundary, which for both structures is reduced to $1.17-1.19 \mathrm{~J} \mathrm{~m}^{-2}$.

More importantly, Ca segregation brings the total energy of the dense structure to a value $0.1 \mathrm{eV} /$ supercell lower than that of the open structure. While this is not a large enough difference to safely conclude that the calculations alone show the Ca-doped dense structure will be the preferred structure, Z-contrast imaging observations strengthen this deduction.

Contour plots of the charge density differences between the ions in the crystal and free atoms calculated for the pure and Ca-doped dense structures of the grain boundary are shown in Fig. 3. It is seen that electron distribution is little affected by the boundary structures or by the segregation of $\mathrm{Ca}$ to the boundary. This implies $\mathrm{Ca}$ stabilization of the grain boundary structure is an elastic rather than electronic effect.

The total density of states calculated for the pure and Ca-doped grain boundaries (Fig. 4) are very similar to that of the bulk crystal, suggesting no major change in the bonding in the grain boundaries. The total density of states also shows that the grain boundary and Ca segregation do not change the width of the band gap and do not induce electronic states in the gap. The calculated band gap is found to be $4.2 \mathrm{eV}$ which, while lower than the experimental value of $7.8 \mathrm{eV}$, is consistent with previous LDA calculations [17].

\section{CONCLUSION}

First-principles density-functional calculations determined that $\mathrm{Ca}$ impurities segregate at particular sites in the dense structure of $\Sigma=5(310)<001>$ tilt grain boundaries in $\mathrm{MgO}$. This segregation induces a structural transformation from the open structure to the dense one. It is also found that both the $\mathrm{Ca}$ impurities and the grain boundaries do not change significantly the total density of states. 
(g) วrmonns əsuəp

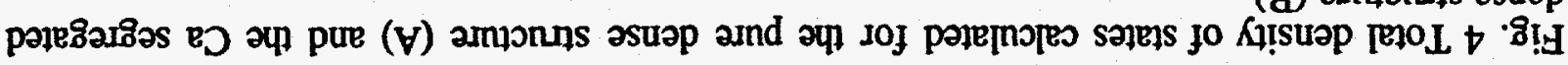

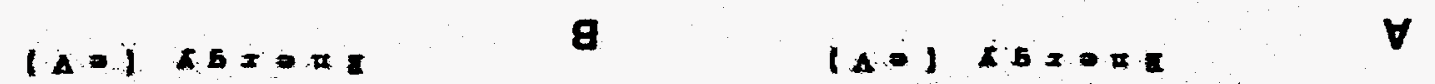
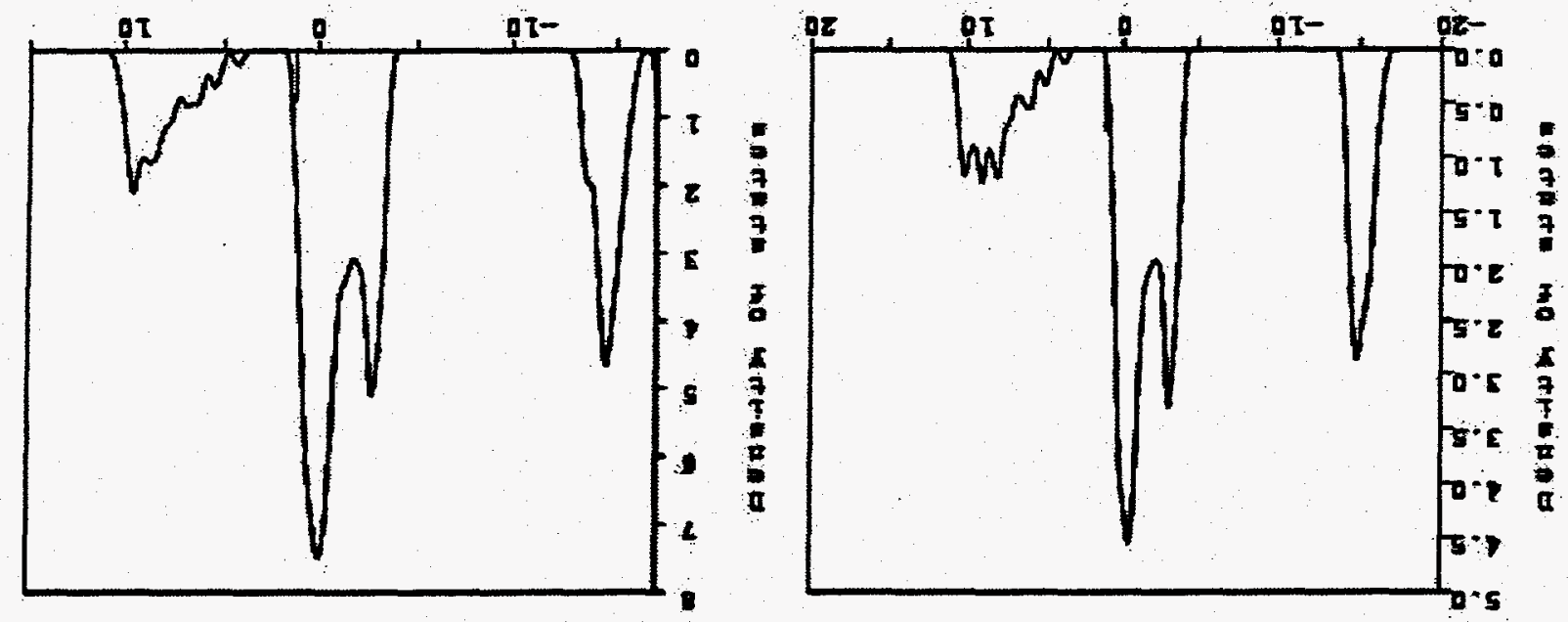

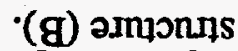

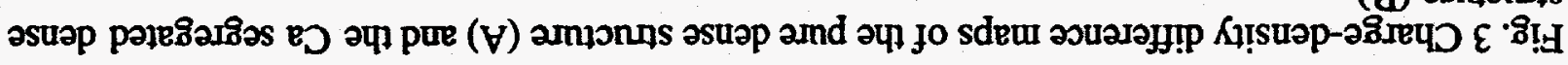
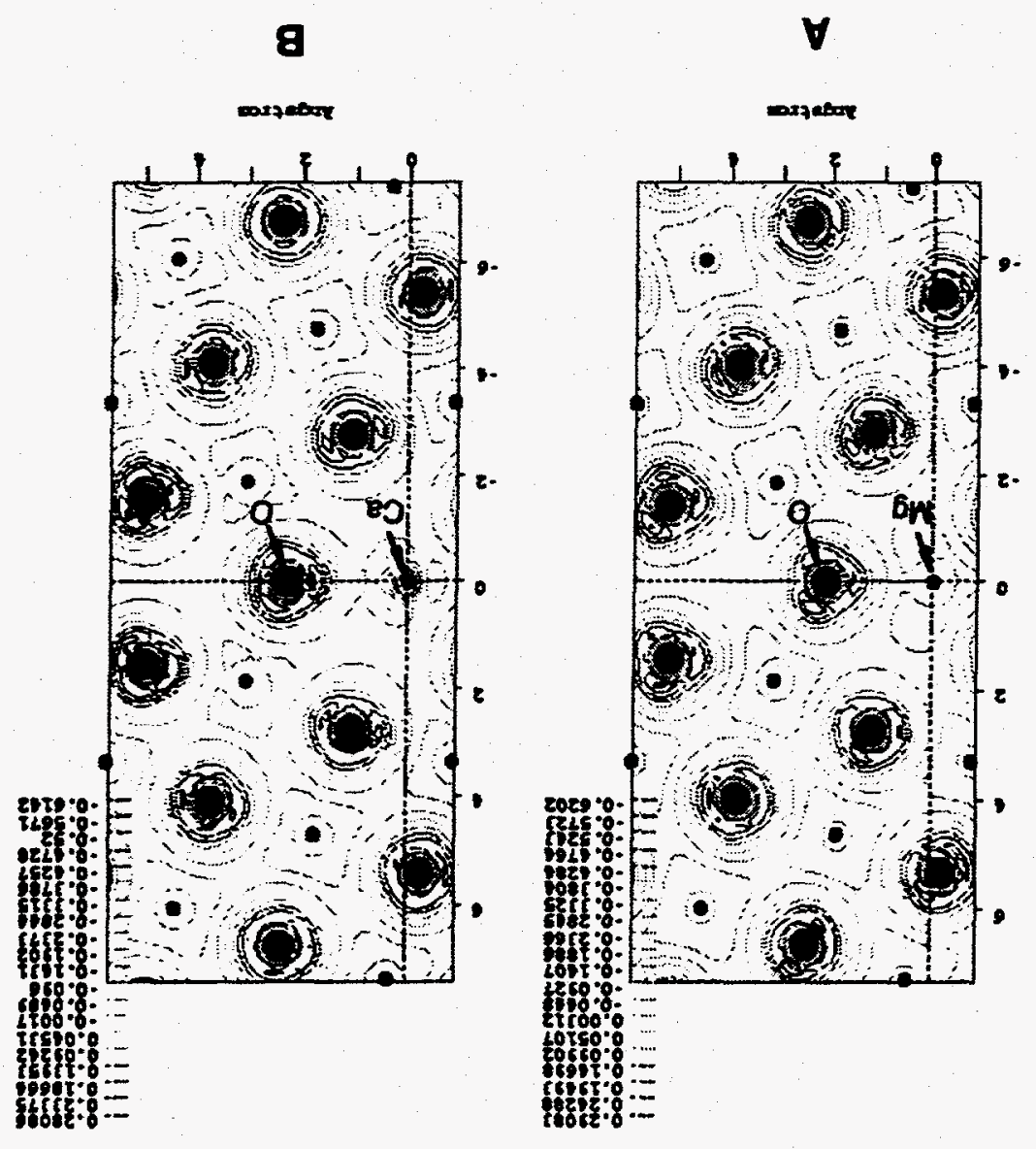


\section{ACKNOWLEDGMENTS}

This research was sponsored by the Division of Materials Sciences, U.S. Department of Energy, under contract DE-AC05-960R22464 with Lockheed Martin Energy Research Corporation, and in part by ORNL's Laboratory Directed Research and Development Fund and by appointment to ORNL Postdoctoral Research Program administered jointly by the Oak Ridge Institute for Science and Education and ORNL.

\section{REFERENCES}

1. V. Vitek and G.J. Wang, Surf. Sci., 144, 110 (1984).

2. K.E. Sickafus and S.L. Sass, Acta Mettall., 35, 69 (1987).

3. C.H. Lin and S.L. Sass, Script Metall., 22, 735 (1988), ibid., p1569.

4. G.H. Li and L.D. Zhang, Scripta Mettall., 32, 1335 (1995).

5. A.P. Sutton and R.W. Balluffi, Interfaces in Crystalline Materials (Oxford Science Publications, Oxford, 1995) and references there in.

6. P. Hohenberg and W. Kohn, Phys. Rev., B136, 864 (1964).

7. J.P. Perdew and A. Zunger, Phys. Rev., B23, 5048 (1981).

8. M.C. Payne, M.P. Teter, D.C. Allen, T.A. Arias and J.D. Joannopoulos, Rev. Mod. Phys., 64, 1045 (1992).

9. W.D. Kingery, J. Amer. Ceram. Soc. , 57, 1 (1974).

10. D.M. Duffy, P.W. and Tasker, Phil. Mag., A 47, 817 (1983).

11. D.J. Harris, G.W. Watson and S.C. Parker, Phil. Mag., A 74407 (1996).

12. T. Kizuka, M. lijima and N. Tanaka, Proc. of Microscopy and Microanalysis, 674 (1996).

13. K.L. Merkle and D.J. Smith, Phys. Rev. Lett, 59, 2887 (1987).

14. P. W. Tasker, J. Chem. Soc. Faraday Trans., 86, 1311 (1990).

15. A. Altermatt and I.D. Brown, Acta Cryst. B41, 240 (1985).

16. I.D. Brown and D. Altermatt, Acta Cryst. B41, 244 (1985).

17. U. Schonberger and F. Aryasetiawan, Phys. Rev., B52, 8788 (1995). 